\title{
Contribution of proton and electron precipitation to the observed electron concentration in October-November 2003 and September 2005
}

\author{
P. T. Verronen ${ }^{1}$, M. E. Andersson ${ }^{1}$, A. Kero ${ }^{2}$, C.-F. Enell ${ }^{3}$, J. M. Wissing ${ }^{4}$, E. R. Talaat ${ }^{5}{ }^{*}$, K. Kauristie $^{1}$, M. Palmroth ${ }^{1}$, \\ T. E. Sarris ${ }^{6}$, and E. Armandillo ${ }^{7}$ \\ ${ }^{1}$ Earth Observation, Finnish Meteorological Institute, Helsinki, Finland \\ ${ }^{2}$ Sodankylä Geophysical Observatory, University of Oulu, Sodankylä, Finland \\ ${ }^{3}$ EISCAT Scientific Association, Kiruna, Sweden \\ ${ }^{4}$ Institute of Environmental Systems Research, University of Osnabrück, Osnabrück, Germany \\ ${ }^{5}$ The Johns Hopkins University Applied Physics Laboratory, Laurel, MD, USA \\ ${ }^{6}$ Space Research Laboratory, Democritus University of Thrace, Xanthi, Greece \\ ${ }^{7}$ European Space Agency, ESTEC, Nordwijk, the Netherlands \\ * present address: NASA Headquarters, Washington, D.C., USA
}

Correspondence to: P. T. Verronen (pekka.verronen@fmi.fi)

Received: 10 October 2014 - Revised: 5 March 2015 - Accepted: 6 March 2015 - Published: 23 March 2015

\begin{abstract}
Understanding the altitude distribution of particle precipitation forcing is vital for the assessment of its atmospheric and climate impacts. However, the proportion of electron and proton forcing around the mesopause region during solar proton events is not always clear due to uncertainties in satellite-based flux observations. Here we use electron concentration observations of the European Incoherent Scatter Scientific Association (EISCAT) incoherent scatter radars located at Troms $\varnothing\left(69.58^{\circ} \mathrm{N}, 19.23^{\circ} \mathrm{E}\right)$ to investigate the contribution of proton and electron precipitation to the changes taking place during two solar proton events. The EISCAT measurements are compared to the results from the Sodankylä Ion and Neutral Chemistry Model (SIC). The proton ionization rates are calculated by two different methods - a simple energy deposition calculation and the Atmospheric Ionization Model Osnabrück (AIMOS v1.2), the latter providing also the electron ionization rates. Our results show that in general the combination of AIMOS and SIC is able to reproduce the observed electron concentration within $\pm 50 \%$ when both electron and proton forcing is included. Electron contribution is dominant above $90 \mathrm{~km}$, and can contribute significantly also in the upper mesosphere especially during low or moderate proton forcing. In the case of strong proton forcing, the AIMOS electron ionization rates seem to
\end{abstract}

suffer from proton contamination of satellite-based flux data. This leads to overestimation of modelled electron concentrations by up to $90 \%$ between $75-90 \mathrm{~km}$ and up to $100-150 \%$ at $70-75 \mathrm{~km}$. Above $90 \mathrm{~km}$, the model bias varies significantly between the events. Although we cannot completely rule out EISCAT data issues, the difference is most likely a result of the spatio-temporal fine structure of electron precipitation during individual events that cannot be fully captured by sparse in situ flux (point) measurements, nor by the statistical AIMOS model which is based upon these observations.

Keywords. Ionosphere (Ion chemistry and composition; Particle precipitation; Polar ionosphere)

\section{Introduction}

Solar energetic particle precipitation affects the neutral composition of the upper stratosphere, mesosphere and lower thermosphere in the polar regions (Sinnhuber et al., 2012; Verronen and Lehmann, 2013). Ionization caused by precipitating protons and electrons leads to changes in a variety of hydrogen and nitrogen species, which ultimately can decrease the ozone concentration. It has been suggested that the middle atmospheric ozone changes due to particle 
precipitation may modulate regional ground-level climate on solar cycle timescales (Rozanov et al., 2005; Seppälä et al., 2009; Baumgaertner et al., 2011). Most of the precipitating particles deposit their energy in the mesosphere and lower thermosphere, and the connection to stratospheric ozone then requires descent of produced odd nitrogen inside the wintertime polar vortex (Callis and Lambeth, 1998; Siskind et al., 2000; Randall et al., 2009; Päivärinta et al., 2013). The altitude of initial odd nitrogen production is important for the efficiency of the odd nitrogen descent, especially around the mesopause where the wintertime mean circulation changes vertical direction (Smith et al., 2011).

When modelling the mesospheric effects of solar proton events (SPE), it is typically assumed that the ionization by electrons is negligible below the mesopause, although in some cases there is ionospheric evidence of simultaneous electron precipitation significantly adding to the ionization caused by the protons (Verronen et al., 2006; Clilverd et al., 2007). Around the mesopause the transition to increasing auroral electron input leads to electron dominance at the upper altitudes. Understanding this transition is an important issue to the odd nitrogen production and descent, because a bulk production above the mesopause is less likely to have an impact on stratospheric ozone.

SPE ionization and most of the subsequent stratospheric and lower mesospheric effects can be reasonably well modelled using proton flux observations from geostationary orbiting satellites (Funke et al., 2011). The electron forcing and effects are much more uncertain because satellite-based magnetospheric flux observations suffer from incomplete spatial and temporal coverage as well as contamination issues especially at higher energies (Rodger et al., 2010a). The Atmospheric Ionization Module Osnabrück (AIMOS) provides a 3 -D atmospheric ionization data with a $2 \mathrm{~h}$ resolution (Wissing and Kallenrode, 2009), but ultimately the electron flux observations used in the calculation determine the quality of the results. A separate validation of observed fluxes of precipitating electrons by comparing observed and modelled changes in mesospheric odd hydrogen indicate a general agreement (Verronen et al., 2013). The agreement was obtained during strong magnetic storms at latitudes connecting to the outer radiation belt, albeit for a limited energy/altitude range only, whereas large adjustments of electron flux observations have been suggested to explain ground-based ionospheric observations (Hendry et al., 2012; Clilverd et al., 2012).

In this paper we use EISCAT incoherent scatter radar measurements of two SPEs (October-November 2003 and September 2005) to study the contribution of proton and electron precipitation to the observed electron density in the mesosphere-lower thermosphere region. We compare the observations to the results from three runs of Sodankylä Ion and Neutral Chemistry model (SIC), designed to separate the effects of protons and electrons. Recently, Wissing et al. (2011) have made a similar study comparing EISCAT and also other incoherent scatter radar electron densities to those calculated using a combination of AIMOS (v1.1) and the Hamburg Model of the Neutral and Ionized Atmosphere (HAMMONIA). They showed that by including electron precipitation the model results became comparable to the EISCAT observations, while without electrons the modelled electron densities were greatly underestimated. In their statistical approach, they were restricted to thermospheric comparisons due to missing $\mathrm{D}$ region ion chemistry in their model, and thus could only study the contribution of auroral-energy electrons. The use of the SIC model in this work allows us to extend the comparison to altitudes below $95 \mathrm{~km}$, thus including effects of high-energy protons and electrons, and study the transition between proton and electron impact, albeit we only consider two selected SPE periods, partly due to the EISCAT observations being less frequently made in the $\mathrm{D}$ region. In contrast to the statistical study by Wissing et al. (2011), our study provides new information on the usability of AIMOS ionization rates in case studies of individual events.

The great storm of October-November 2003, a.k.a. the Halloween storm, is one of the most studied SPEs of the space age, particularly because of the numerous satellite observations of ozone and ozone-depleting species that were available at the time (e.g. Jackman et al., 2008; Funke et al., 2011, and references therein). There are also a number ionospheric studies considering this event (e.g. Verronen et al., 2005; Clilverd et al., 2006; Osepian et al., 2009). However, these previous ionospheric studies either used measurements which do not provide detailed altitude-dependent information and/or concentrated on proton forcing in the $\mathrm{D}$ region (below $90 \mathrm{~km}$ altitude). In our current work, we study the response of the ionosphere in a wider range of altitudes, concentrate on the transition region around the mesopause, and consider the effects of both electron and proton precipitation.

\section{EISCAT data}

The EISCAT (European Incoherent Scatter) Scientific Association is an international research organization operating three incoherent scatter radar systems to study the interaction between the Sun and the Earth as revealed by disturbances in the magnetosphere and the ionized parts of the atmosphere. The EISCAT radars measure profiles of electron density, electron and ion temperature, and a simple parametrization of ion composition, by fitting theoretical lag profiles to lag profiles decoded from the received signal (Nygrén, 1996). The lag profile is a discrete representation of the autocorrelation function (which forms a Fourier transform pair with the incoherent scatter spectrum) convolved with the so-called ambiguity function representing the space and time resolution of a given radar pulse code. In the data analysis, the current EISCAT software (GUISDAP) takes into account (a) measured transmitter power, (b) antenna gains and range (radar equation), and (c) receiver response from injection of a known 
Table 1. Selected characteristics of the data and the events. pfu: proton flux unit ( $>10 \mathrm{MeV}$ protons cm $\left.^{-2} \mathrm{~s}^{-1} \mathrm{sr}^{-1}\right)$. Magnetic Ap index is an indicator of the magnitude of electron precipitation.

\begin{tabular}{lrr}
\hline Event & $\begin{array}{r}\text { Case 1 } \\
\text { October-November 2003 }\end{array}$ & $\begin{array}{r}\text { Case 2 } \\
\text { September 2005 }\end{array}$ \\
\hline Start day & 26 Oct & 8 Sep \\
$p f u$ maximum & $29500(28$ Oct $)$ & $1880(11 \mathrm{Sep})$ \\
$A_{p}$ maximum & $203.9(29 \mathrm{Oct})$ & $100.8(11 \mathrm{Sep})$ \\
Solar F10.7 maximum & $275.4(30 \mathrm{Oct})$ & $117.6(11 \mathrm{Sep})$ \\
Solar X-ray maximum & X17 (28 Oct) & X17 (7 Sep) \\
EISCAT radar & VHF 224 MHz & UHF 928 MHz \\
EISCAT dates & 28 Oct-2 Nov & $6-9 \mathrm{Sep}$ \\
EISCAT temporal resolution & $0.4 \mathrm{~s}$ & $90 \mathrm{~s}$ \\
EISCAT experiment & arc_dlayer & tau2pl \\
EISCAT altitudes & $60-130 \mathrm{~km}$ & $50-700 \mathrm{~km}$ \\
EISCAT calibration & ionosonde & IS plasma line \\
\hline
\end{tabular}

noise source in the antenna. For quantitative retrieval of the electron density, the results must be calibrated. There are two options: either the electron density from the E or F2 layer peak is compared to observations of a nearby EISCAT ionosonde, or the electron plasma frequency is used as a direct measurement of the electron density. Not all experiments modes provide plasma line measurements, though.

Here we consider two periods of solar proton events: The October-November 2003 event, a.k.a. the Halloween 2003 event (which we call Case 1 from now on), and September 2005 event (Case 2). These two are very different in magnitude. Case 1 was the 4 th largest SPE in the past 50 years while Case 2 was 15 th when sorted according to total $\mathrm{NO}_{\mathrm{x}}$ production in the middle atmosphere which is linearly proportional to the ionization caused by the events (Jackman et al., 2008). Details on these events and the utilized EISCAT data are given in Table 1. More information on the SPE events can be found in e.g. Funke et al. (2011) and Damiani et al. (2008). EISCAT data and more detailed descriptions of the radars and measurement modes are available from their web site (https://www.eiscat.se, accessed in February 2014). Note that we reduced the temporal resolution of the EISCAT observations to $2 \mathrm{~h}$ by averaging.

During Case 1 the $224 \mathrm{MHz}$ VHF radar was operated. The experiment pulse code used was arc_dlayer, which has a time resolution of about $0.4 \mathrm{~s}$ and a sub-kilometre range resolution from 60 to $130 \mathrm{~km}$. This mode uses only the ion line receiver and does not provide plasma lines (i.e. it is ionosonde-calibrated). The VHF antenna cannot be pointed south of the zenith direction due to RF interference issues, so the VHF measurements are never aligned with the magnetic field. During this experiment the antenna elevation was moved from vertical to northward as necessary to reach lower altitudes at given ranges. In Case 2 the UHF radar operating in the $930 \mathrm{MHz}$ band was used. The pulse code programme was tau $2 p l$, which saves plasma lines (e.g. for calibration) and covers ranges from 50 to above $700 \mathrm{~km}$, but has poorer range and time resolution as compared to dedicated D-layer experiments. This and the higher frequency makes this experiment less accurate in the $\mathrm{D}$ region. During this experiment the antenna was scanning in the pattern designated $C P 2$ (https://www.eiscat.se/about/experiments $2 /$ scans), i.e. vertical, field-aligned, and two positions around the field line in 90 s intervals. Thus in Case 2 the data are mostly from positions south of the site.

The ionospheric parameters are inverted from the radar observations using a parametrized backscatter spectrum based on the assumption that electron density fluctuations are caused by ion-acoustic plasma waves. This incoherent scatter radar (ISR) theory works for the ionospheric $\mathrm{E}$ and $\mathrm{F}$ regions in many (but not all) cases. For the collision-dominated lower ionosphere however, this analysis method, as implemented in GUISDAP, does not necessarily give proper estimates of electron density. Furthermore, a proper analysis of the D region backscatter spectrum requires long lags calculated by inter-pulse correlations, which the current GUISDAP software cannot handle.

In Case 1, it became obvious that the GUISDAP-analysed EISCAT data suffered seriously from an inadequate D region ISR theory implementation, which led up to 700-800\% differences between modelled and observed electron concentrations below about $90 \mathrm{~km}$ (positive model bias, not shown). For this reason we perform the model-EISCAT comparison in Case 1 using the EISCAT observations of pseudobackscatter power, which can be calculated in arbitrary units from the first lags and is assumed to be directly related to electron density. In order to convert these to absolute values of electron concentration, which we can then compare with the model results, we calibrated the backscatter power against the GUISDAP measurements to give the same electron concentration at $90-110 \mathrm{~km}$, where the GUISDAP implementation of ISR theory is valid. During the calibration we also normalized the results with radar power which varies 
with time. However, the effect of this normalization is relatively small, i.e. on average about $7 \%$.

In Case 2, the standard GUISDAP analysis provided data down to $77 \mathrm{~km}$ only. Therefore, we repeated the analysis using the GUISDAP "ppshortlags" option which extended the data down to lower altitudes. This analysis uses shorter lags to estimate the electron density from backscattered power, similar to our analysis of Case 1 data. GUISDAP then also performed the scaling of the power to electron density and the correction for radar transmitter power.

\section{Particle ionization rates}

The AIMOS model (http://aimos.physik.uos.de/, accessed in September 2013) provides 3-D (latitude, longitude, altitude) ionization rates for atmospheric modelling with high spatial resolution (Wissing and Kallenrode, 2009). AIMOS is based on statistical maps of precipitation and Monte Carlo calculation of energy deposition. For protons, it utilizes satellite data from the NOAA Polar Orbiting Satellites (POES N15/N16 for 2002-2005 and N17/18 onward) and the geostationary GOES satellites (GOES-10 for 2002-2003, GOES-11 onward). In addition to protons, AIMOS also provides ionization rates due to electron and alpha particle precipitation. The electron rates are calculated using POES observations. The energy resolution is given by the particle detectors on POES and GOES. Thus AIMOS v1.2 has nine proton channels from POES ranging from $154 \mathrm{eV}$ up to $6.9 \mathrm{MeV}$, six proton channels from GOES covering 4-500 MeV, and seven electron channels from POES ranging from $154 \mathrm{eV}$ up to $2.5 \mathrm{MeV}$. A more detailed description on all the channels used in AIMOS is given by Wissing and Kallenrode (2009). The particle spectrum for both protons and electrons is fitted by up to five power laws. Therefore AIMOS can take care for eventually different steepnesses that might occur e.g. at the transition between different solar and magnetospheric particle populations. The amount of power laws and the energy range of each of them is selected by the correlation coefficient of the generated fit and the measured channel values. Since the characteristic particle energies depend on the steepness of the particle spectrum (here: the fit) they are determined numerically by iterative fitting. Note that bremsstrahlung by energetic electrons is considered in AIMOS, but its contribution to the ionization is negligible in the altitude range of this study.

In addition to AIMOS, for comparison, we calculated ionization rates due to proton precipitation using a continuously slowing-down approximation (from now on called CSDA). The CSDA method uses observations on the seven channels of the geostationary GOES-11 satellite, which measures integrated fluxes at energies larger than 1, 5, 10, 30, 50, 60 and $100 \mathrm{MeV}$. These data are available online at the NOAA National Geophysical Data Center (http://spidr.ngdc.noaa.gov/ spidr/). An integrated proton flux can be described by an ex- ponential rigidity relation (Freier and Webber, 1963), which is used to convert the GOES measurements to differential proton fluxes over the energy range of $1-500 \mathrm{MeV}$ on a grid of 78 logarithmically spaced energies. The shape of the resulting spectrum is Maxwellian. The ionization rate calculation follows the approach presented in detail by Verronen et al. (2005), originally presented by Reid (1961), and are based on empirical energy-range relation for protons (Bethe and Ashkin, 1953). Thus above $4 \mathrm{MeV}$ both CSDA and AIMOS use GOES proton flux data but are methodologically very different. Before the calculation, we reduced the original 5 min time resolution of GOES proton flux observation to $2 \mathrm{~h}$ by averaging.

\section{Model setup}

The SIC model is a 1-D tool for ionospheric and middle atmospheric studies. The latest version includes a chemical scheme of about 400 reactions and solves the concentrations of 43 positive ions, 29 negative ions, and 16 neutral species between $20-150 \mathrm{~km}$ altitude with $1 \mathrm{~km}$ resolution. The background neutral atmosphere, e.g. $\mathrm{N}_{2}$ and $\mathrm{O}_{2}$, and temperature are calculated using the empirical NRLMSISE-00 model (Picone et al., 2002) which depends on daily values of solar F10.7 radio flux and magnetic Ap index. The daily solar spectrum is calculated using the SOLAR2000 empirical solar irradiance model (Tobiska et al., 2000), version V2.37. In addition to solar radiation, SIC is driven by solar energetic particles, i.e. electron and proton precipitation, as well as galactic cosmic rays. A more detailed description of SIC is given by Verronen et al. (2005) and Turunen et al. (2009). Note that electron concentration of the mesosphere-lower thermosphere transition region can be readily studied with SIC which includes a detailed description of $\mathrm{D}$ region ion chemistry.

All the SIC model runs were made at the EISCAT Troms $\varnothing$ location $\left(69.58^{\circ} \mathrm{N}, 19.23^{\circ} \mathrm{E}\right)$. Before modelling the events, we initialized the SIC model to pre-SPE conditions on 25 October 2003 and 5 September 2005 for Case 1 and Case 2, respectively. We then made four model runs for both SPE events, the runs differing in particle precipitation forcing as listed in Table 2. The CSDA and AIMOS ionization rates were calculated with $2 \mathrm{~h}$ temporal resolution. AIMOS calculates the rates on a $3.6^{\circ}$-by- $3.6^{\circ}$ latitude-longitude grid, and in the modelling we used rates averaged between 68.58 $70.58^{\circ} \mathrm{N}$ and $18.23-20.23^{\circ} \mathrm{E}$, corresponding best to the EISCAT radar location in Troms $\varnothing$. The model runs were made for 27 October-5 November and 6-9 September for Case 1 and Case 2, respectively. Note that before the EISCAT-SIC comparisons presented in Sect. 5, we corrected the modelled electron concentrations for the Debye-length and negative ion effects (for details, see e.g. Fukuyama and Kofman, 1980). After this correction, which is important in the 
Table 2. Particle ionization rates used in the SIC model runs.

\begin{tabular}{lll}
\hline Run & Protons & Electrons \\
\hline SIC1 & None & None \\
SIC2 & CSDA $(E>1 \mathrm{MeV})$ & None \\
SIC3 & CSDA $(E>1 \mathrm{MeV})$ & AIMOS $(E>154 \mathrm{eV})$ \\
SIC4 & AIMOS $(E>154 \mathrm{eV})$ & AIMOS $(E>154 \mathrm{eV})$ \\
\hline
\end{tabular}

D region, the model results are directly comparable the EISCAT measurements at all altitudes considered here.

\section{Results}

The calculated proton and electron ionization rates for the two events, time-integrated over the EISCAT observation days, are shown in Fig. 1. For Case 1, electron and proton effects peak at about 110 and $60 \mathrm{~km}$ indicating strongest forcing by $6 \mathrm{keV}$ and $20 \mathrm{MeV}$ particle energies, respectively (for the energy-altitude relations, see e.g. Turunen et al., 2009, Fig. 3). The electron forcing exceeds that by protons (both from AIMOS) above $84 \mathrm{~km}$, and above $92 \mathrm{~km}$ its proportion is $74-88 \%$ of the total (sum of AIMOS protons and electrons). At altitudes below $70 \mathrm{~km}$, the electron proportion is less than $20 \%$ of the total. Comparing the proton forcing from CSDA and AIMOS, the profiles show similar altitude behaviour below $90 \mathrm{~km}$, although the AIMOS values are consistently about a factor of 2 larger. With increasing altitude CSDA eventually shows orders of magnitude lower values compared to AIMOS because of the exclusion of lower proton energies in the CSDA calculations (first channel of GOES-11 is $1 \mathrm{MeV}$, corresponding to about $90 \mathrm{~km}$ altitude). For Case 2, due to relatively weaker proton forcing, the electron proportion is $80-90 \%$ at above $96 \mathrm{~km}$, and exceeds the proton forcing down to $72 \mathrm{~km}$ (Fig. 1). In this case, the AIMOS proton forcing is a factor of 2-4 larger than that from CSDA, and the altitude profiles are again similar/different at altitudes below/above $90 \mathrm{~km}$. Below $90 \mathrm{~km}$, the largest difference is seen around $30 \mathrm{~km}$, corresponding to proton energies of about $200 \mathrm{MeV}$. At these altitudes, beyond the last GOES energy channel of $100 \mathrm{MeV}$, the differences in ionization are strongly affected by different spectral shape assumptions: AIMOS assumes a multiple power-law spectrum while CSDA uses a Maxwellian shape.

Figure 2 presents the temporal behaviour of calculated ionization rates. We have selected altitudes 70 and $110 \mathrm{~km}$ to represent the behaviour of the forcing in the mesosphere (protons) and lower thermosphere (electrons), respectively. In Case 1, the proton ionization varies by 5 orders of magnitude during the event, with a clear peak in forcing between 28 and 31 October. The variation in electron ionization is smaller than that of protons but still reaches nearly 3 orders of magnitude. The difference is that the proton ionization varies more gradually while the electron forcing has alter- nating maxima and minima throughout the event. The situation is similar in Case 2, although with less variability in the magnitude of the ionization ( 3 and 2 orders of magnitude for protons and electrons, respectively). In this case, the proton ionization remains low until increasing substantially on 8-9 September.

The modelled electron concentrations resulting from the proton and electron forcing are shown in Figs. 3 and 4, together with the EISCAT observations. Different to the ion pair production, the electron concentrations rapidly decrease below about $70 \mathrm{~km}$ (the altitude depending on particle forcing and day/night conditions) to values $<10^{8} \mathrm{~m}^{-3}$, because large part of the negative charge created by ionization is converted to negative ions (e.g. Verronen et al., 2006). For both Case 1 and Case 2, the EISCAT data show maximum concentrations of over $10^{11} \mathrm{~m}^{-3}$ at altitudes above $100 \mathrm{~km}$ where the electron forcing is dominant. Comparing the model results to EISCAT electron concentrations, the two runs including AIMOS electrons (SIC3 and SIC4) show similar altitude behaviour. The differences in proton ionization calculation between SIC3 and SIC4 seem to have a relatively small impact on the electron concentrations. In contrast, the run with $>1 \mathrm{MeV}$ protons only (SIC2) strongly affecting altitudes below $90 \mathrm{~km}$, clearly underestimates the electron concentration at higher altitudes. Instead of showing more or less continuous impact by electrons, as seen in EISCAT, SIC 3 and SIC4, the electron concentration displays a diurnal cycle due to solar EUV ionization. On top of this, the intensity variations of the SPE are seen in electron concentration below $100 \mathrm{~km}$.

Figures 5 and 6 show the EISCAT-SIC electron concentration comparison at selected altitudes. Above $100 \mathrm{~km}$, it is again obvious that the model runs including AIMOS electron ionization (SIC3 and SIC4) agree best with the EISCAT data overall and that the other runs (SIC1 and SIC2) are generally underestimating the electron concentration, especially at nighttime, by up to 2 orders of magnitude. At $90 \mathrm{~km}$, also the run with proton ionization only (SIC2) becomes comparable to EISCAT during periods of strong proton ionization (28-31 October, 9 September). Reaching the lower limit of EISCAT observations, Case 1 comparison at $70 \mathrm{~km}$ shows a slight overestimation of electron concentrations by all model runs including particle forcing (SIC2, SIC3 and SIC4) during the SPE peak (28-31 October), while later on (1-2 November) the agreement with the observations is best for the SIC 3 and SIC4 runs. In Case 2, at $70 \mathrm{~km}$, there is an overall agreement between EISCAT and SIC3 and SIC4 runs. Note that the run without any proton or electron ionization (SIC1) underestimates the electron concentration compared to EISCAT at all altitudes and times by orders of magnitude. In both cases and all altitudes, the differences between SIC3 and SIC4, using different proton ionization rates, is relatively small.

Some of the EISCAT data show a clear EUV-related variability, especially in Case 2 (Fig. 6). This is seen at the upper altitudes at daytime when the small differences between the 

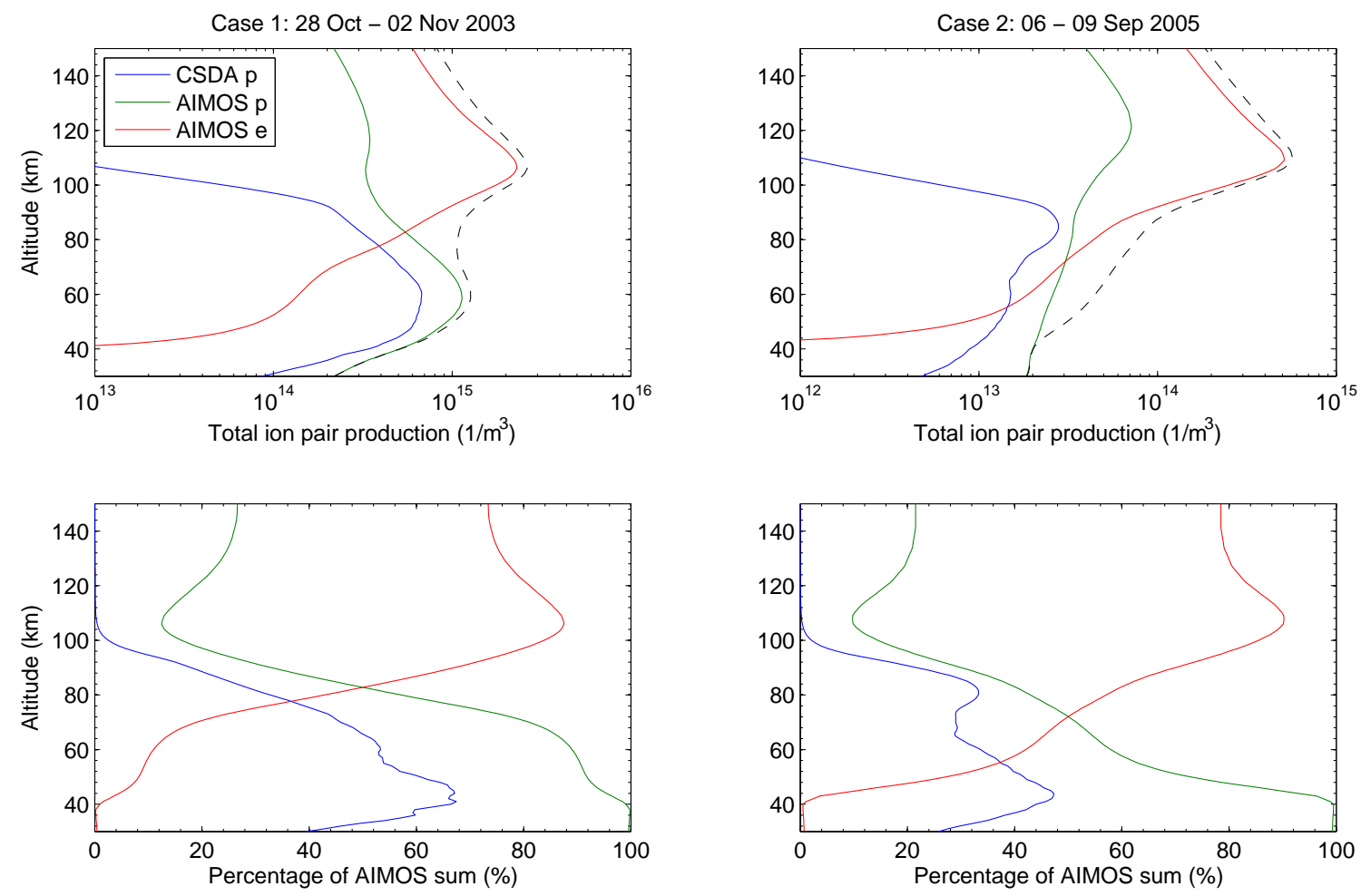

Figure 1. Top: integrated ion-electron pair production by CSDA (protons only) and AIMOS (protons and electrons separately). The dashed black line is the sum of AIMOS (protons and electrons). Bottom: relative proportion compared to the AIMOS sum.
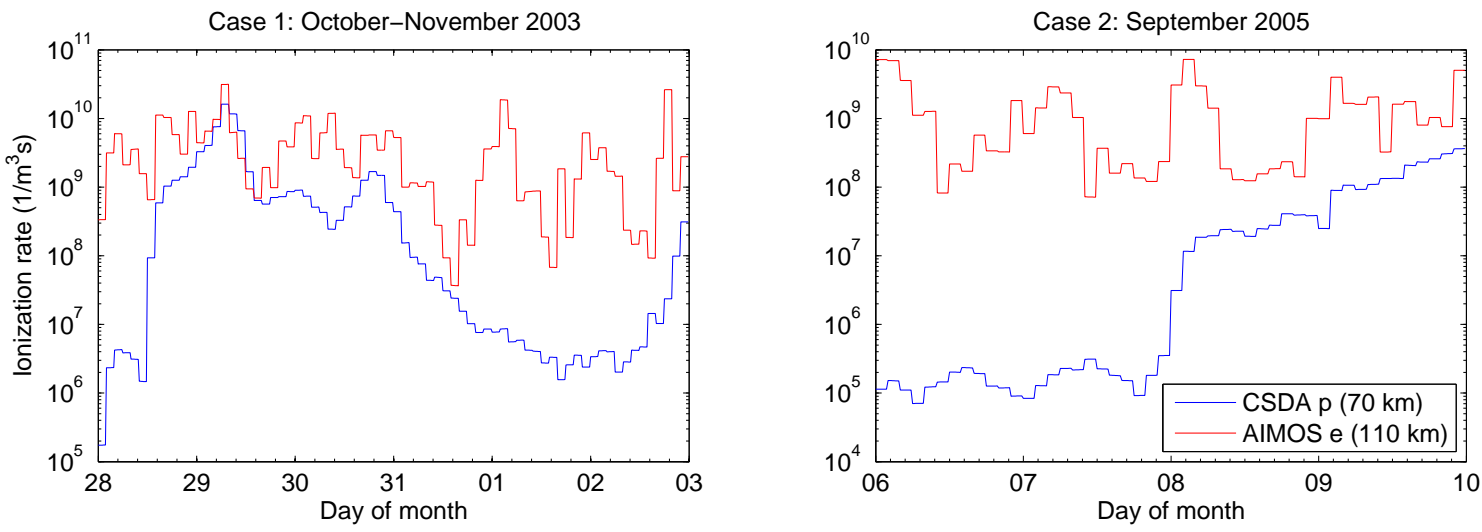

Figure 2. Calculated ionization rates due to protons (CSDA) and electrons (AIMOS) at 70 and $110 \mathrm{~km}$, respectively.

model runs indicate a relatively small contribution from particle precipitation (around 12:00 UT on 7 and 8 September). The controlling role of EUV ionization leads to a smaller standard deviation of EISCAT data in these daytime periods compared to nighttime which is controlled by more varying particle forcing. Because we are interested in the quality of particle forcing in our model, we excluded the EUVcontrolled points from the statistical analysis of SIC-EISCAT differences. This was done by selecting time periods which (1) have a difference larger than a factor of 4 between the SIC4 and SIC1 runs or (2) have solar zenith angle $>100^{\circ}$.
The data points selected for the following comparison are indicated in Figs. 5 and 6 with the red circles.

Figure 7 and Tables 3 and 4 present the median differences in electron concentration between the EISCAT observations and the model results. In Case 1, inclusion of AIMOS electrons leads to good agreement with EISCAT above $90 \mathrm{~km}$, the difference being much less than the median standard deviation (MSTD) of the observations. The best general agreement with EISCAT, $\pm 15 \%$, is with the model run including ionization by both CSDA protons and AIMOS electrons (SIC3). The run including AIMOS protons and electrons 

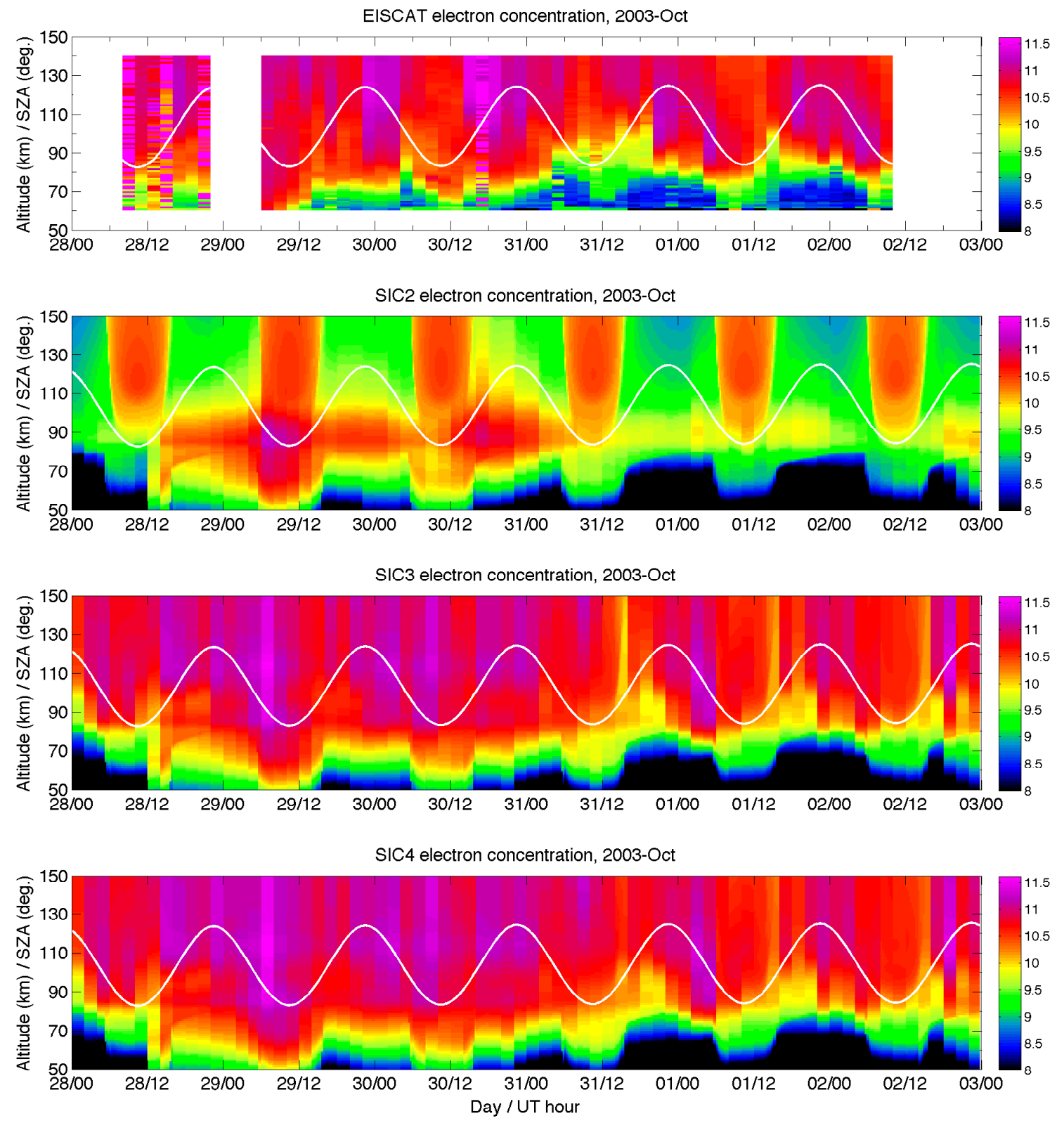

Figure 3. Electron concentrations (10-base logarithm of $\mathrm{m}^{-3}$ ) from EISCAT and the three SIC model runs for the October-November 2003 event (Case 1). The white line shows the diurnal cycle of the solar zenith angle at the EISCAT Troms $\varnothing$ location.

(SIC4) shows a positive bias of up to $30 \%$ although at altitudes above $120 \mathrm{~km}$ the bias is very small and smaller than with SIC3. The runs without AIMOS electrons (SIC1 and SIC2) show a large negative bias between -30 and $-95 \%$. Below $90 \mathrm{~km}$, the bias of SIC3 and SIC4 increases rapidly, and the relative values for SIC3 exceed 30 and $100 \%$ at 80 and $70 \mathrm{~km}$, respectively. Below $85 \mathrm{~km}$ SIC2 shows the smallest bias, less than $25 \%$ which is within the EISCAT MSTD. Compared to Case 1, in Case 2 the results have a similar altitude behaviour although the magnitude of bias differs. Above $110 \mathrm{~km}$, SIC3 and SIC4 exhibit bias between -35 and $-60 \%$, which is larger than MSTD of the observations.
At $90-110 \mathrm{~km}$, the bias is smaller, between -15 and $-55 \%$, which at these altitudes is generally within MSTD. And below $90 \mathrm{~km}$, the bias is generally within the MSTD while gradually turning positive and reaching $85-110 \%$ at $70 \mathrm{~km}$. The runs without AIMOS electrons, SIC1 and SIC2, show larger negative biases between -80 and $-100 \%$ above $100 \mathrm{~km}$. At altitudes below, the SIC1 bias exceeds $-90 \%$ at all altitudes while SIC2 bias gets gradually smaller with decreasing altitude, being between -35 and $+5 \%$ below $85 \mathrm{~km}$, which is within MSTD. 

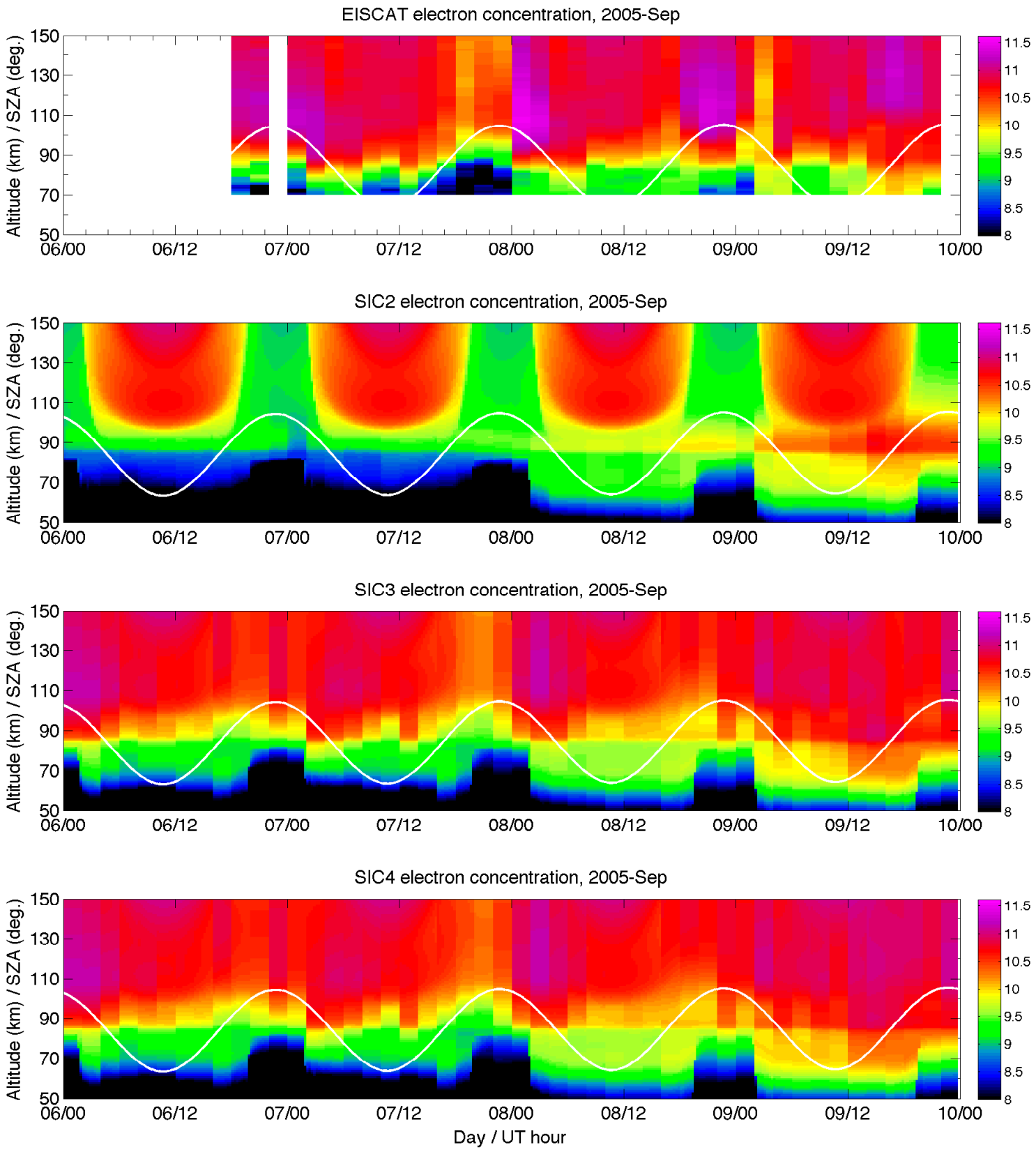

Figure 4. As Fig. 2, but for the September 2005 event (Case 2).

\section{Discussion}

Overall, our results show that by including both the proton and electron ionization the modelled electron concentrations are comparable to those observed by the EISCAT radar. The main issues are: (a) Case 1 and Case 2 below $90 \mathrm{~km}$, where the model bias shows a clear change compared to the altitudes above, and (b) Case 2 above $110 \mathrm{~km}$, where the bias is larger than the EISCAT MSTD. Nevertheless, the temporal behaviour of electron concentration is still similar to the observations in all cases and at all altitudes.
Looking at the electron concentration comparisons in Figs. 5-7, the two events considered here differ in model bias above $90 \mathrm{~km}$. The discrepancy between EISCAT and the model runs including both proton and electron ionization (SIC3 and SIC4) is clearly larger in Case 2. This could be related to either problems in the modelled proton/electron forcing or differences in the measurements coming from two different radars. Below we discuss some of the potential issues related to the comparison.

The fact that the radars were pointing at different directions (see Sect. 2) during the two events should not matter 

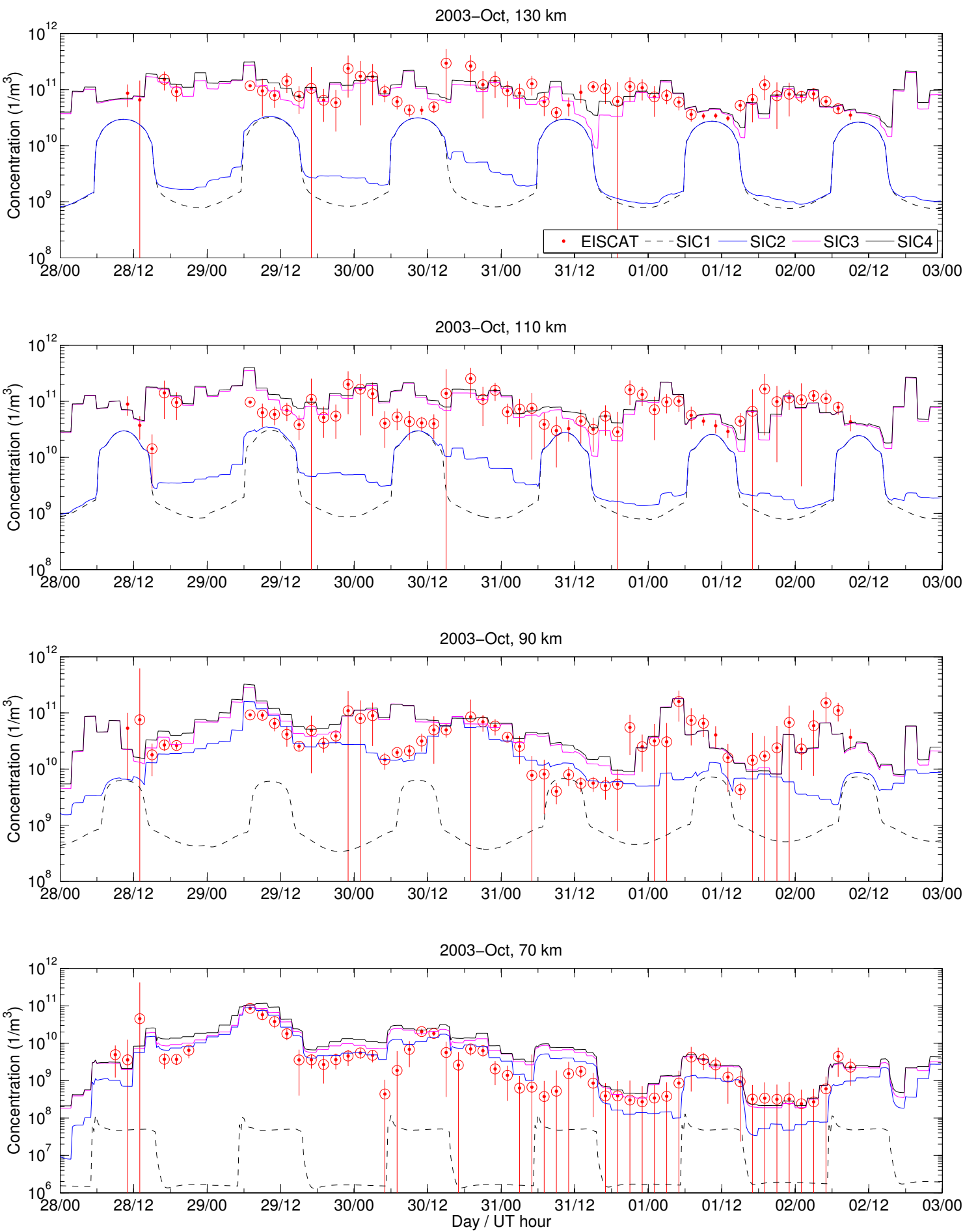

Figure 5. Electron concentration comparison between EISCAT and the four SIC model runs at selected altitudes for the OctoberNovember 2003 event (Case 1). The vertical red lines indicate the uncertainties (standard deviation) of the $2 \mathrm{~h}$ EISCAT averages. The red circles indicate the data points that were selected for statistical comparison.

for the protons, because the high-energy part of the proton precipitation is more of less homogeneous at geomagnetic latitudes above $60^{\circ}$, see e.g. Bornebusch et al. (2010). Also Wissing and Kallenrode (2009) discuss the differ- ent behaviour of low-energy and high-energy protons and show that the $0.8-2.5 \mathrm{MeV}$ channel on POES already has an homogeneously filled polar cap at $\mathrm{Kp}=3.3$. Because the measurements (at Troms $\varnothing$ ) are located at $66.73^{\circ}$ corrected 

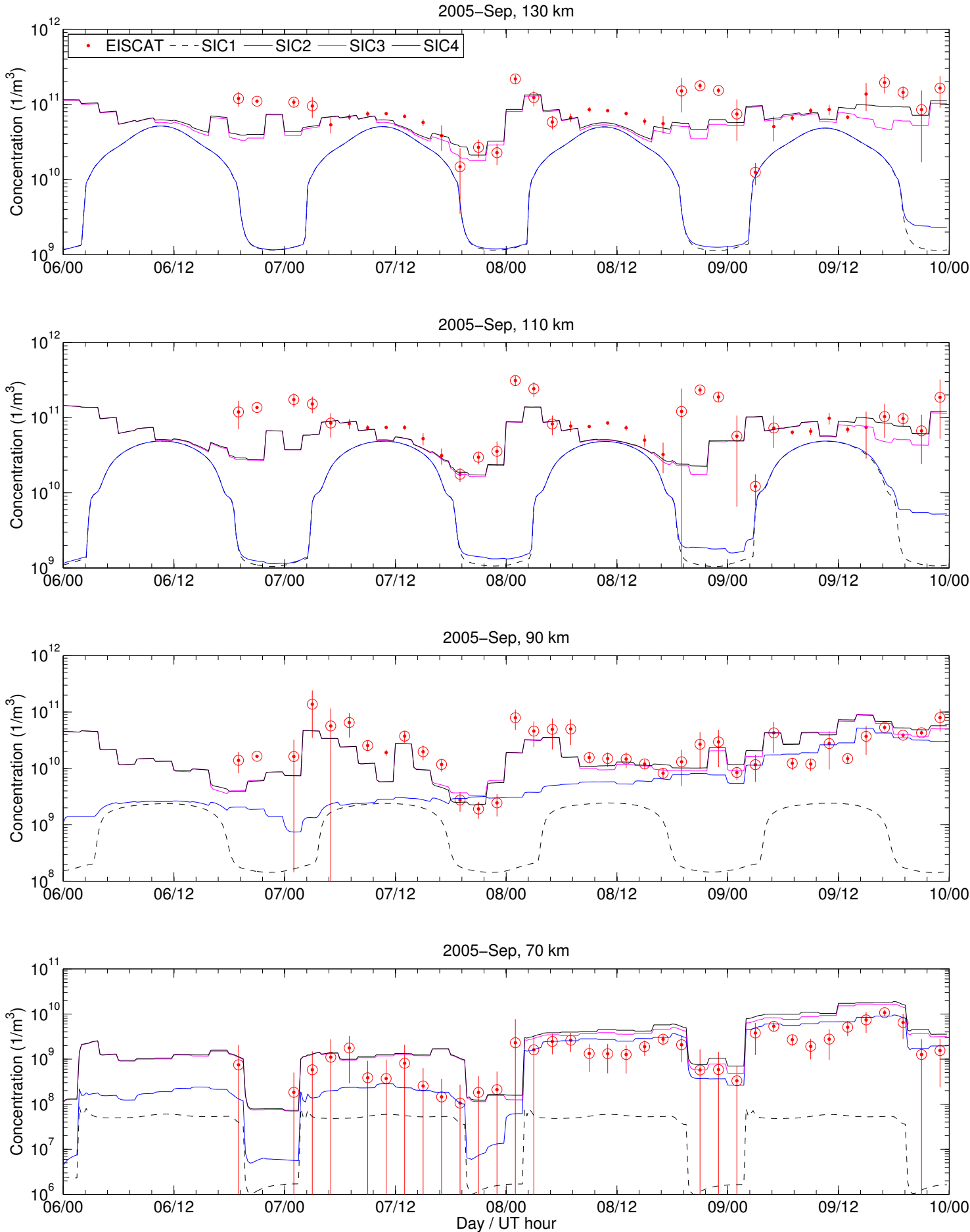

Figure 6. As Fig. 4, but for the September 2005 event (Case 2).

geomagnetic latitude, homogeneous precipitation for highenergy protons ( $>4 \mathrm{MeV}$ for AIMOS) can be assumed. And at proton energies less than $4 \mathrm{MeV}$ AIMOS uses spatially resolved POES data, as it does for the complete electron contribution. But since electron precipitation typically has fine structures both spatially and temporally, ionization rates calculated from statistical average spectra (e.g. in AIMOS) could simply be representing the electron flux at the direction of the radar better during Case 1 . However, since no two events are exactly the same, and thus average spectra may or may not be comparable with any one-point measurement by EISCAT, the "best" direction for the radar will likely 

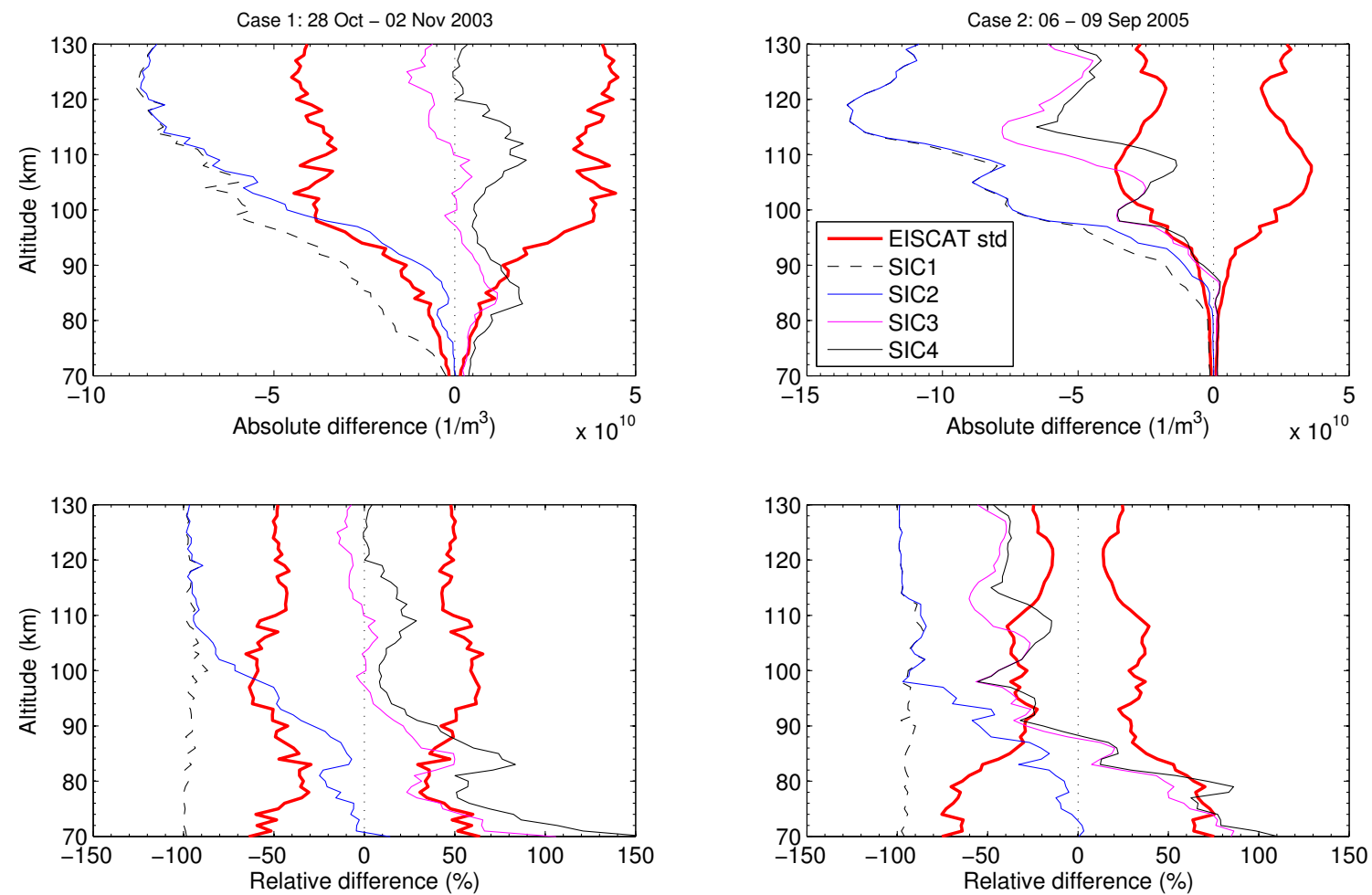

Figure 7. Top: absolute difference of the median electron concentration of the four SIC runs and EISCAT observations. The thick red line indicates the median of EISCAT standard deviation, while zero indicates the median of the EISCAT measurements. Bottom: the same, but as relative difference to the median EISCAT electron concentration.

Table 3. Median relative differences in electron concentration between the SIC model runs and EISCAT observations between 28 October and 2 November 2003 (Case 1). The values in bold face indicate the smallest difference at the corresponding altitude.

\begin{tabular}{rrrrr}
\hline Altitude & SIC1 & SIC2 & SIC3 & SIC4 \\
\hline $130 \mathrm{~km}$ & $-96 \%$ & $-96 \%$ & $-7 \%$ & $\mathbf{+ 4 \%}$ \\
$120 \mathrm{~km}$ & $-96 \%$ & $-95 \%$ & $-6 \%$ & $\mathbf{+ 0} \%$ \\
$110 \mathrm{~km}$ & $-96 \%$ & $-94 \%$ & $\mathbf{+ 0 \%}$ & $+20 \%$ \\
$100 \mathrm{~km}$ & $-86 \%$ & $-71 \%$ & $\mathbf{+ 0} \%$ & $+8 \%$ \\
$90 \mathrm{~km}$ & $-94 \%$ & $-28 \%$ & $\mathbf{+ 2 1} \%$ & $+40 \%$ \\
$80 \mathrm{~km}$ & $-97 \%$ & $\mathbf{- 2 1} \%$ & $+31 \%$ & $+57 \%$ \\
$70 \mathrm{~km}$ & $-98 \%$ & $\mathbf{+ 1 3} \%$ & $+104 \%$ & $+156 \%$ \\
\hline
\end{tabular}

vary from event to event. Therefore, in single-event comparisons, such as the one presented here, a one-to-one match between models not resolving precipitation fine structure and EISCAT observations cannot be expected at all times and locations. Note also that AIMOS uses a $400 \mathrm{~km}$ resolution (in north-to-south direction $3.6^{\circ}$ ). Thus all the ionization data for the Troms $\emptyset$ location is from one grid cell in AIMOS, while ionization rate from one cell to the next can vary by orders of magnitude. Taking all this into account, it seems that the statistical validation approach presented by Wissing et al. (2011) is a better measure of the overall AIMOS
Table 4. As Table 3, but between 6 and 9 September 2005 (Case 2).

\begin{tabular}{rrrrr}
\hline Altitude & SIC1 & SIC2 & SIC3 & SIC4 \\
\hline $130 \mathrm{~km}$ & $-98 \%$ & $-98 \%$ & $-55 \%$ & $\mathbf{- 4 6 \%}$ \\
$120 \mathrm{~km}$ & $-97 \%$ & $-97 \%$ & $-44 \%$ & $\mathbf{- 3 9 \%}$ \\
$110 \mathrm{~km}$ & $-90 \%$ & $-87 \%$ & $-53 \%$ & $\mathbf{- 1 9 \%}$ \\
$100 \mathrm{~km}$ & $-93 \%$ & $-93 \%$ & $-44 \%$ & $\mathbf{- 4 4 \%}$ \\
$90 \mathrm{~km}$ & $-89 \%$ & $-54 \%$ & $-28 \%$ & $\mathbf{- 1 9 \%}$ \\
$80 \mathrm{~km}$ & $-92 \%$ & $\mathbf{- 7} \%$ & $+47 \%$ & $+71 \%$ \\
$70 \mathrm{~km}$ & $-95 \%$ & $\mathbf{+ 0 \%}$ & $+84 \%$ & $+110 \%$ \\
\hline
\end{tabular}

model performance. Nevertheless, our results provide important information about the possible issues in a singleevent study. In future, if funded, the EISCAT_3D project (https://www.eiscat3d.se, accessed in September 2014) will be able to provide 3-D measurements of e.g. electron concentration. This would be a huge asset in event studies like the present one.

It seems unlikely that the different results for the two events are an EISCAT calibration issue. This is because we find rather good agreement (within $\pm 50 \%$, Fig. 7) between EISCAT and the model (SIC4) almost everywhere else but below $90 \mathrm{~km}$ in Case 1 and below $80 \mathrm{~km}$ in Case 2. Note also that even at these altitudes the agreement seems to be better when the ionization is weaker (e.g. bottom panel of Fig. 5), 
indicating a possible issue with the particle ionization forcing.

Keeping in mind the issues related to the EISCAT data, as pointed out above, we now discuss the differences between EISCAT and the model runs from the point of view of proton and electron forcing. In Case 1, the best agreement with EISCAT at $90-120 \mathrm{~km}$ is from the model including CSDA protons and AIMOS electrons (SIC3). Note that the CSDA proton forcing above $90 \mathrm{~km}$ is likely not realistic due to its $1 \mathrm{MeV}$ lower energy limit. Thus the fact that SIC3 gives a better fit to EISCAT data than SIC4 (which includes AIMOS protons and electrons) seems to indicate that the electron forcing from AIMOS is somewhat overestimated. However, since both SIC3 and SIC4 are well within the EISCAT median STD range, the agreement is clearly good for both model runs. At altitudes below $90 \mathrm{~km}$, both SIC 3 and SIC4 give too large electron concentrations. This behaviour could be related to strong proton contamination of POES MEPED electron channels (Rodger et al., 2010a; Yando et al., 2011). This is supported by the fact the SIC2 run (including protons only) is in best agreement with EISCAT below $90 \mathrm{~km}$. Note that although the absolute values of electron concentration differ, the temporal variation seems to be similar in EISCAT and the model runs (Fig. 5, bottom panel). In Case 2, the underestimation of electron density by the model runs (SIC3 and SIC4) above $90 \mathrm{~km}$ indicates underestimation of electron forcing by AIMOS because the contribution of protons is much smaller, and especially so above $110 \mathrm{~km}$ where the difference is outside the EISCAT MSTD. Below $90 \mathrm{~km}$, the positive model bias again suggests possible proton contamination of the electron flux observations. Note, however, that compared to the large variation caused by the particle forcing the within-50\% bias in the model results (SIC4, above $80 \mathrm{~km}$ ) is still relatively small.

It is known that AIMOS v1.2 can overestimate the electron forcing at some altitudes due to two main issues: (a) enhanced electron ionization between 50 and $70 \mathrm{~km}$ due to an unknown (and probably incorrect) upper threshold of the MEPED e3 channel (see Yando et al., 2011, for details and Funke et al., 2011, for the effects on atmospheric ionization modelling), and (b) contamination of MEPED electron detectors (cross-talking) especially during solar proton events (Rodger et al., 2010a). However, we can assume that our results are not affected by issue (a) because EISCAT is limited to altitudes above $70 \mathrm{~km}$. On the other hand, issue (b) is the most likely reason for the positive model bias below $90 \mathrm{~km}$ (Fig. 7, bottom panels, SIC3 and SIC4 runs). The effect of issue (b) on electron concentration has not been quantified before. Now, however, the model-EISCAT comparison gives a first estimate: $40-150 \%$ positive bias at $90-70 \mathrm{~km}$ for Case 1 (SIC4 run).

In Case 2, above $110 \mathrm{~km}$ there is about a factor of 2 difference between EISCAT and SIC in the EUV-controlled daytime periods (Fig. 6, top panels). However, at this point we are not able to identify the reason for the difference. A pos- sible solution would be to increase the NO concentration in the model, so that its EUV ionization would become comparable to those of $\mathrm{O}_{2}$ and $\mathrm{N}_{2}$. Indeed, in the Case 2 period the SIC NO concentrations are a factor of 2-4 lower at 110$130 \mathrm{~km}$ than those observed by the ACE-FTS satellite instrument at $60-63^{\circ} \mathrm{N}$ (not shown). However, based on the modelled ionization rates we estimate that an increase in NO by a factor of 40 would be needed to reduce the EISCAT-SIC difference in electron concentration. Therefore, this does not seem like a plausible explanation. Associated with the SPE of September 2005, there was also a X-class solar flare observed on 7 September (Xiong et al., 2011). However, because the reported enhancements in electron concentration were restricted to the time of the flare (17:40-18:10 UT), the hard X-ray ionization caused by the flare cannot explain the all-daytime EISCAT-SIC difference on 7 or 8 September.

Finally, there is about a factor of 2 difference in proton ionization rates between the CSDA method and AIMOS at altitudes below $90 \mathrm{~km}$, as shown in Fig. 1. After considering possible differences in proton spectrum (although both use GOES satellite data), we found that the difference comes from the different fraction of the spectral energy being deposited in the atmosphere. Given that the Geant4-based ionization algorithm in AIMOS conserves energy, our investigation implies that the CSDA method can be further improved by quantitative scaling, e.g. by normalizing the total ionization energy to that of the proton spectrum. Note that the different proton ionization rates lead to relatively small differences in electron concentration compared to the orders-ofmagnitude variability caused by the events (Figs. 5 and 6). On average over the event, and at altitudes $70-130 \mathrm{~km}$, SIC4 gives up to 25 and $15 \%$ higher electron concentration compared to SIC 3 for Case 1 and Case 2, respectively.

\section{Summary}

In this paper we have used the Sodankylä Ion and Neutral Chemistry (SIC) model to study the electron concentration in the upper mesosphere-lower thermosphere during two solar proton events. The particle ionization rates were calculated using POES and GOES satellite observations of electron and proton fluxes and AIMOS v1.2 ionization model. The SIC model results were compared to observations of EISCAT incoherent scatter radars. Our main conclusions are:

1. Electron concentration of the upper mesosphere/lower thermosphere can be reasonably well modelled using AIMOS v1.2 ionization rates, except at 70-90 km during strong proton forcing. Our case study is in agreement with Wissing et al. (2011), who showed a reasonable statistical agreement in thermospheric electron concentration between the HAMMONIA model and EISCAT observations when AIMOS ionization rates were included. 
2. Our results clearly indicate that electron precipitation is an important source of ionization: above $90 \mathrm{~km}$ even during strong solar proton forcing and also below mesopause when proton forcing is moderate or weak.

3. Above $90 \mathrm{~km}$, the SIC-EISCAT difference can vary considerably from event to event. This does not seem to be related to EISCAT data, although we cannot rule the possibility of calibration issues out completely. Most likely, however, it is caused by the statistical nature of AIMOS ionization not capturing all the spatio-temporal fine structure of electron precipitation. The EISCAT radar pointing direction could also play a role in explaining the differences between events. This might be of special interest for future single-point or single-event studies.

4. Below $90 \mathrm{~km}$, the AIMOS electron ionization seems to be overestimated during strong solar proton forcing, probably because of proton contamination of the POES MEPED electron detectors. In the two cases considered here, this leads to overestimation of modelled electron concentrations by up to $90 \%$ between $75-90 \mathrm{~km}$ and up to $100-150 \%$ at $70-75 \mathrm{~km}$. It should be noted that the most recent AIMOS version discards electron measurements in the case of potential proton contamination. Whether this completely eliminates the positive bias during SPEs might be an interesting topic for future studies.

Acknowledgements. The work of P. T. Verronen, M. E. Andersson, E. R. Talaat, K. Kauristie, M. Palmroth and T. E. Sarris was funded by the European Space Agency through the project "Electrodynamics Study of the Upper Atmosphere in Support to Future MLTI missions" (ITT: AO/1-6690/11/NL/AF, PI: T. E. Sarris). P. T. Verronen and M. E. Andersson were also supported by the Academy of Finland through the projects \#136225, \#140888, and \#272782 (SPOC: Significance of Energetic Electron Precipitation to Odd Hydrogen, Ozone, and Climate). P. T. Verronen and J. M. Wissing would like to thank the International Space Science Institute, Bern, Switzerland for their support for the "Quantifying Hemispheric Differences in Particle Forcing Effects on Stratospheric Ozone" team. C.-F. Enell acknowledges funding from the European Union's Seventh Framework Programme for research, technological development and demonstration under grant agreement no. 283676, NearEarth Space Data Infrastructure for e-Science (ESPAS). The authors would like to thank the anonymous reviewers for their valuable comments. We are indebted to the director and staff of EISCAT for operating the facility and supplying the data. EISCAT is an international association supported by research organizations in China (CRIRP), Finland (SA), Japan (NIPR and STEL), Norway (NFR), Sweden (VR) and the United Kingdom (NERC).

Topical Editor K. Hosokawa thanks two anonymous referees for their help in evaluating this paper.

\section{References}

Baumgaertner, A. J. G., Seppälä, A., Jöckel, P., and Clilverd, M. A.: Geomagnetic activity related $\mathrm{NO}_{\mathrm{x}}$ enhancements and polar surface air temperature variability in a chemistry climate model: modulation of the NAM index, Atmos. Chem. Phys., 11, 45214531, doi:10.5194/acp-11-4521-2011, 2011.

Bethe, A. H. and Ashkin, J.: Passage of Radiations through Matter, vol. 1 of Experimetal Nuclear Physics, edited by: Segre, E., pp. 166-251, John Wiley \& Sons, Inc., New York, USA, 1953.

Bornebusch, J. P., Wissing, J. M., and Kallenrode, M.-B.: Solar particle precipitation into the polar atmosphere and their dependence on hemisphere and local time, Adv. Space Res., 45, 632-637, 2010.

Callis, L. B. and Lambeth, J. D.: $\mathrm{NO}_{y}$ formed by precipitating electron events in 1991 and 1992: Descent into the stratosphere as observed by ISAMS, Geophys. Res. Lett., 25, 1875-1878, doi:10.1029/98GL01219, 1998.

Clilverd, M. A., Seppälä, A., Rodger, C. J., Thomson, N. R., Verronen, P. T., Turunen, E., Ulich, T., Lichtenberger, J., and Steinbach, P.: Modelling polar ionospheric effects during the OctoberNovember 2003 solar proton events, Radio Sci., 41, RS2001, doi:10.1029/2005RS003290, 2006.

Clilverd, M. A., Rodger, C. J., Millan, R. M., Sample, J. G., Kokorowski, M., McCarthy, M. P., Ulich, T., Raita, T., Kavanagh, A. J., and Spanswick, E.: Energetic particle precipitation into the middle atmosphere triggered by a coronal mass ejection, J. Geophys. Res., 112, A12206, doi:10.1029/2007JA012395, 2007.

Clilverd, M. A., Rodger, C. J., Danskin, D., Usanova, M. E., Raita, T., Ulich, T., and Spanswick, E. L.: Energetic Particle injection, acceleration, and loss during the geomagnetic disturbances which upset Galaxy 15, J. Geophys. Res., 117, A12213, doi:10.1029/2012JA018175, 2012.

Damiani, A., Storini, M., Laurenza, M., and Rafanelli, C.: Solar particle effects on minor components of the Polar atmosphere, Ann. Geophys., 26, 361-370, doi:10.5194/angeo-26-361-2008, 2008.

Freier, P. S. and Webber, W. R.: Exponential Rigidity Spectrums for Solar-Flare Cosmic Rays, J. Geophys. Res., 68, 1605-1629, 1963.

Fukuyama, K. and Kofman, W.: Incoherent scattering of an electromagnetic wave in the mesosphere: A theoretical consideration, $\mathrm{J}$. Geomag. Geoelectr., 32, 67-81, 1980.

Funke, B., Baumgaertner, A., Calisto, M., Egorova, T., Jackman, C. H., Kieser, J., Krivolutsky, A., López-Puertas, M., Marsh, D. R. Reddmann, T., Rozanov, E., Salmi, S.-M., Sinnhuber, M., Stiller, G. P., Verronen, P. T., Versick, S., von Clarmann, T., Vyushkova, T. Y., Wieters, N., and Wissing, J. M.: Composition changes after the "Halloween" solar proton event: the High Energy Particle Precipitation in the Atmosphere (HEPPA) model versus MIPAS data intercomparison study, Atmos. Chem. Phys., 11, 90899139, doi:10.5194/acp-11-9089-2011, 2011.

Hendry, A. T., Rodger, C. J., Clilverd, M. A., Thomson, N. R., Morley, S. K., and Raita, T.: Rapid radiation belt losses occurring during high speed solar wind stream driven storms: importance of energetic electron precipitation, in: Dynamics of the Earth's Radiation Belts and Inner Magnetosphere, edited by: Summers, D., Mann, I. R., Baker, D. N., and Schulz, M., vol. 199 of American Geophysical Union Monograph, pp. 213-223, American Geophysical Union, doi:10.1029/2012GM001299, 2012. 
Jackman, C. H., Marsh, D. R., Vitt, F. M., Garcia, R. R., Fleming, E. L., Labow, G. J., Randall, C. E., López-Puertas, M., Funke, B., von Clarmann, T., and Stiller, G. P.: Short- and medium-term atmospheric constituent effects of very large solar proton events, Atmos. Chem. Phys., 8, 765-785, doi:10.5194/acp-8-765-2008, 2008.

Nygrén, T.: Introduction to incoherent scatter measurements, no. 1 in Invers Publications, Invers Oy, Sodankylä, Finland, 1996.

Osepian, A., Kirkwood, S., Dalin, P., and Tereschenko, V.: D-region electron density and effective recombination coefficients during twilight - experimental data and modelling during solar proton events, Ann. Geophys., 27, 3713-3724, doi:10.5194/angeo-273713-2009, 2009.

Päivärinta, S.-M., Seppälä, A., Andersson, M. E., Verronen, P. T., Thölix, L., and Kyrölä, E.: Observed effects of solar proton events and sudden stratospheric warmings on odd nitrogen and ozone in the polar middle atmosphere, J. Geophys. Res., 118, 6837-6848, doi:10.1002/jgrd.50486, 2013.

Picone, J. M., Hedin, A. E., Drob, D. P., and Aikin, A. C.: NRLMSISE-00 empirical model of the atmosphere: Statistical comparisons and scientific issues, J. Geophys. Res., 107, 1468, doi:10.1029/2002JA009430, 2002.

Randall, C. E., Harvey, V. L., Siskind, D. E., France, J., Bernath, P. F., Boone, C. D., and Walker, K. A.: $\mathrm{NO}_{\mathrm{x}}$ descent in the Arctic middle atmosphere in early 2009, Geophys. Res. Lett., 36, L18811, doi:10.1029/2009GL039706, 2009.

Reid, G. C.: A study of the enhanced ionization produced by solar protons during a polar cap absorbtion event, J. Geophys. Res., 66, 4071-4085, 1961.

Rodger, C. J., Clilverd, M. A., Green, J. C., and Lam, M. M.: Use of POES SEM-2 observations to examine radiation belt dynamics and energetic electron precipitation into the atmosphere, J. Geophys. Res., 115, A04202, doi:10.1029/2008JA014023, 2010a.

Rozanov, E., Callis, L., Schlesinger, M., Yang, F., Andronova, N., and Zubov, V.: Atmospheric response to $\mathrm{NO}_{y}$ source due to energetic electron precipitation, Geophys. Res. Lett., 32, L14811, doi:10.1029/2005GL023041, 2005.

Seppälä, A., Randall, C. E., Clilverd, M. A., Rozanov, E., and Rodger, C. J.: Geomagnetic activity and polar surface air temperature variability, J. Geophys. Res., 114, A10312, doi:10.1029/2008JA014029, 2009.

Sinnhuber, M., Nieder, H., and Wieters, N.: Energetic particle precipitation and the chemistry of the mesosphere/lower thermosphere, Surv. Geophys., 33, 1281-1334, doi:10.1007/s10712012-9201-3, 2012.

Siskind, D. E., Nedoluha, G. E., Randall, C. E., Fromm, M., and Russell III, J. M.: An assessment of Southern Hemisphere stratospheric $\mathrm{NO}_{\mathrm{x}}$ enhancements due to transport from the upper atmosphere, Geophys. Res. Lett., 27, 329-332, 2000.
Smith, A. K., Rolando, R. R., Marsh, D. R., and Richter, J. H.: WACCM simulations of the mean circulation and trace species transport in the winter mesosphere, J. Geophys. Res., 116, D20115, doi:10.1029/2011JD016083, 2011.

Tobiska, W. K., Woods, T., Eparvier, F., Viereck, R., Floyd, L. D. B., Rottman, G., and White, O. R.: The SOLAR2000 empirical solar irradiance model And forecast tool, J. Atmos. Sol.-Terr. Phys., 62, 1233-1250, 2000.

Turunen, E., Verronen, P. T., Seppälä, A., Rodger, C. J., Clilverd, M. A., Tamminen, J., Enell, C.-F., and Ulich, T.: Impact of different precipitation energies on $\mathrm{NO}_{\mathrm{x}}$ generation during geomagnetic storms, J. Atmos. Sol.-Terr. Phys., 71, 1176-1189, doi:10.1016/j.jastp.2008.07.005, 2009.

Verronen, P. T. and Lehmann, R.: Analysis and parameterisation of ionic reactions affecting middle atmospheric $\mathrm{HO}_{\mathrm{x}}$ and $\mathrm{NO}_{\mathrm{y}}$ during solar proton events, Ann. Geophys., 31, 909-956, doi:10.5194/angeo-31-909-2013, 2013.

Verronen, P. T., Seppälä, A., Clilverd, M. A., Rodger, C. J., Kyrölä, E., Enell, C.-F., Ulich, T., and Turunen, E.: Diurnal variation of ozone depletion during the October-November 2003 solar proton events, J. Geophys. Res., 110, A09S32, doi:10.1029/2004JA010932, 2005.

Verronen, P. T., Ulich, Th., Turunen, E., and Rodger, C. J.: Sunset transition of negative charge in the D-region ionosphere during high-ionization conditions, Ann. Geophys., 24, 187-202, doi:10.5194/angeo-24-187-2006, 2006.

Verronen, P. T., Andersson, M. E., Rodger, C. J., Clilverd, M. A., Wang, S., and Turunen, E.: Comparison of modeled and observed effects of radiation belt electron precipitation on mesospheric hydroxyl and ozone, J. Geophys. Res., 118, 1141911428, doi:10.1002/jgrd.50845, 2013.

Wissing, J. M. and Kallenrode, M.-B.: Atmospheric Ionization Module Osnabrück (AIMOS): A 3-D model to determine atmospheric ionization by energetic charged particles from different populations, J. Geophys. Res., 114, A06104, doi:10.1029/2008JA013884, 2009.

Wissing, J. M., Kallenrode, M.-B., Kieser, J., Schmidt, H., Rietveld, M. T., Strømme, A., and Erickson, P. J.: Atmospheric Ionization Module Osnabrück (AIMOS): 3. Comparison of electron density simulations by AIMOS-HAMMONIA and incoherent scatter radar measurements, J. Geophys. Res., 116, A08305, doi:10.1029/2010JA016300, 2011.

Xiong, B., Wan, W., Liu, L., Withers, P., Zhao, B., Ning, B., Wei, Y., Le, H., Ren, Z., Chen, Y., He, M., and Liu, J.: Ionospheric response to the X-class solar flare on 7 September 2005, J. Geophys. Res., 116, A11317, doi:10.1029/2011JA016961, 2011.

Yando, K., Millan, R. M., Green, J. C., and Evans, D. S.: A Monte Carlo simulation of the NOAA POES Medium Energy Proton and Electron Detector instrument, J. Geophys. Res., 116, A10231, doi:10.1029/2011JA016671, 2011. 